\title{
Ten health stories that mattered: Jan. 6-10
}

- The first North American death from H5N1 (avian flu) occurred in Alberta. The deceased had just returned from China. Health officials say the strain is not easily transmitted between humans and there is no public threat.

- Deaths from H1N1 flu have been recorded in several provinces, including nine in Alberta and six in Saskatchewan. H1N1 is the dominant strain of this year's flu season, accounting for most lab-confirmed cases of flu-related hospitalizations.

- The federal government will not pay for the refugee health care program recently set up by the Ontario government, according to the office of the Minister of Citizenship and Immigration. Ontario reinstated access to essential and urgent health care for refugee claimants in December and said it would "send the federal government the bill to pay for the program."

- The federal government announced $\$ 63$ million in funding for 250 research facilities in 37 Canadian universities. Medical research receiving funding include the creation of a portable brain scanner for detecting brain injuries, early identification of molecular changes in blood vessels to detect hypertension, and development of intravascular biomaterials for cardiovascular and coagulation disorders.

- Employers should not require sick notes from employees with the flu, according to the Ontario Medical Association. Sick employees seeking notes from doctors risk infecting vulnerable patients in physicians' waiting rooms, such as seniors and those with chronic health conditions, states the press release.

- Newfoundland hospitals are seeing an increase in cases of carbon monoxide poisoning, including one that resulted in death, according to Eastern Health. The province had experienced power outages due to severe weather, and people were being exposed to more engine exhaust because of increased use of generators, snow blowers and propane appliances, states the public service announcement.

- A New Brunswick store owner is refuting a Health Canada order to stop selling e-cigarettes. The store owner claims that the dose of nicotine delivered is too low to be legally classified as a new drug or drug delivery system.

- A British Columbia company is offering to arrange Health Canada authorizations for medical marijuana over Skype to residents of Nova Scotia, reports CBC News. The Medical Cannabis Resource Centre, based in Vancouver, plans to open a clinic in Nova Scotia in March. Meanwhile, for $\$ 400$, it will set up online exams with doctors in British Columbia or Ontario.

- A total of $\$ 2.3$ million in bonuses will be paid to the 704 employees of eHealth Ontario, a provincial agency responsible for creating electronic medical records, reports the Toronto Star. In 2011, the Ontario government cancelled merit raises and bonuses for the agency, which lead to a class-action lawsuit.

- It's been cold out there. Really cold. Very, very cold. So cold that some public health authorities have issued extreme cold warnings, suggesting Canadians wear appropriate clothing to avoid frostbite and hypothermia.

— Roger Collier, CMAJ

CMAJ 2014. DOI:10.1503/cmaj.109-4699 